\title{
Fazendas históricas paulistas dos séculos XVIII e XIX: premissas teóricas e metodológicas para inventariar bens patrimoniais
}

São Paulo state historical farms of the $18^{\text {th }}$ and $19^{\text {th }}$ centurries: theoretical and methodological premisses to inventory historical goods

\section{ELISA Yumi NaKagawa}

Doutora e mestre em Ciências de Computação (USP) e docente do ICMC (USP)

E mail: elisa@icmc.usp.br

\section{Luzia Sigoli Fernandes Costa}

Doutora em Ciência da Informação (Unesp) e docente da UFSCar - São Carlos E-mail: luziasigoli@gmail.com

Rosaelena Scarpeline

Mestre em História (Unicamp) e bibliotecária do Centro de Memória-Unicamp

E-mail: rscarpel@unicamp.br

\section{Resumo}

Os bens patrimoniais das fazendas paulistas, dos séculos XVIII e XIX, constituem-se em importantes fontes para ensino, pesquisa e turismo. No contexto do projeto "Patrimônio Cultural Rural Paulista: Espaço Privilegiado para Pesquisa, Educação e Turismo", apresentase uma proposta teórico-metodológica para inventariar bens patrimoniais.

Palavras-chave: Fazenda histórica paulista; Inventário patrimonial; Padrão de descrição da informação

\section{Abstract}

The historical goods of the São Paulo State farms, built in the 18th and 19th centuries, are an important source of education, research and tourism. In the context of the project "São Paulo State Rural Cultural Patrimony: Privileged Space to the Research, Education and Tourism”, it is presented a theoreticalmethodological proposal in order to inventory the historical goods.

Keywords: São Paulo state historical farm;

Patrimonial inventory; Information description standard 
1 - Projeto de Políticas Públicas "Patrimônio Cultural Rural Paulista: Espaço Privilegiado para Pesquisa, Educação e Turismo", financiado pela Fapesp, processo número 07/55999-1 com período de vigência de 2007 a 2011, tendo como coordenador geral o Prof. Dr. Marcos Tognon do Centro de MemóriaUnicamp (CMU). reservar os registros de dados, de informações e dos saberes tem sido um
dos desafios da sociedade contemporânea. A oralidade, a iconografia,
a escrita, os objetos, dentre outras formas de registros, foram os meios encontrados pela humanidade para deixar o seu legado cultural e intelectual para as gerações futuras e os povos distantes. A inacessibilidade a esses registros e a falta de entendimento das mensagens por eles guardadas limita a nossa capacidade de conhecer, compreender e imaginar os fatos e os feitos que marcaram a trajetória humana, em diferentes momentos e lugares.

Sabemos que há uma diversidade de acervos de inestimável valor histórico e cultural, constituídos por diferentes suportes, preservados pelas instituições como museus, bibliotecas, arquivos, e centros de memória, públicos e privados. No Brasil, podemos considerar o universo das fazendas históricas, surgidas nos séculos XVIII e XIX no interior paulista, como locais que devem dialogar com essas instituições. Pois, essas fazendas constituem-se em inesgotáveis fontes para estudos e pesquisas diante da descoberta da grande diversidade de bens preciosos e raros de natureza material, imaterial e paisagístico.

No contexto de um projeto de políticas públicas, intitulado de "Patrimônio Cultural Rural Paulista: Espaço Privilegiado para Pesquisa, Educação e Turismo”, [1] o nosso principal objetivo tem sido o de desenvolver uma proposta teóricometodológica de inventário, desses bens patrimoniais, que resultassem numa base de dados e de conhecimentos abrangendo conteúdos das ciências e das artes como, também, do censo comum e da cultura popular, visando, assim, sua preservação e divulgação. $\mathrm{O}$ projeto, num primeiro momento, abrangeu quatorze fazendas históricas, dispersas por cinco regiões do Estado de São Paulo que compreende Itu, Campinas-Limeira, Mococa, São Carlos e Vale do Paraíba, com as denominações: Capoava, Chácara do Rosário, Santa Ursula, Quilombo, Fazenda Nova, Santa Cecília, Fazenda Aurora, Santo Antonio d’Água Limpa, Fazenda Pinhal, Santa Maria do Monjolinho, Mandaguahy, Bela Vista, Nossa Senhora da Conceição e São Francisco.

Outras três fazendas foram visitadas pelo grupo de pesquisadores do projeto mais recentemente e passaram a integrar o projeto, sendo elas: Fazenda Santa Eudóxia (em São Carlos), Fazenda Bela Aliança (em Descalvado) e Fazenda Restauração (no município de Queluz). Essas fazendas são represen- 
tativas de períodos como o da cana de açúcar, no século XVIII, do café, no século XIX, e até mesmo da pecuária, no século XX, e pertencem à macro região conhecida historicamente como alta mogiana.

Os pesquisadores envolvidos nesse projeto possuem diferentes formações acadêmicas e pertencem a associações [2] e várias instituições como o Instituto Agronômico (IA), a Embrapa - Monitoramento de Satélite e universidades públicas e privadas dos Estados de São Paulo e do Rio de Janeiro, sendo elas: Universidade Estadual de Campinas (Unicamp), Universidade de São Paulo (USP) campus de São Carlos e USP Leste, Universidade Estadual Paulista (Unesp) campus de Rosana, Universidade Federal de São Carlos (UFSCar), Universidade Federal Rural do Rio de Janeiro (UFRRJ) e Universidade Metodista de Piracicaba (Unimep). A reunião desses pesquisadores possibilitou a constituição de uma equipe pluridisciplinar e o estabelecimento de compromissos com a proposição de metodologias que possam contribuir para aprimorar os processos de identificação, descrição, gestão, conservação e difusão do expressivo patrimônio rural paulista. Os resultados desses processos trazem contribuições importantes não só para os gestores das fazendas, mas, também para os pesquisadores interessados em temáticas pertinentes ao universo rural brasileiro ou aquelas relacionadas com a preservação patrimonial, mas também para um grande público que passou a olhar para as fazendas históricas como um lugar de memória, de conhecimento e de turismo cultural e, portanto, educativo.

Nessa perspectiva, nossa proposta reside em construir um sistema web livre, denominado Memória Virtual Rural, que dê conta de abarcar e disponibilizar um amplo rol de dados, informações e conhecimentos, sobre todas as áreas envolvidas, bem como as informações sobre os diferentes tipos de bens patrimoniais que possam vir a ser encontrados nesses espaços rurais, por meio de plataforma web. Vale destacar o caráter inédito desse sistema, inclusive, em âmbito internacional, em face de suas pretensões de abrangência, exaustividade e profundidade. Para a construção desse sistema, tem sido de grande importância o desenvolvimento de uma base metodológica, sustentada por um instrumento que denominamos de Padrão de Descrição de Informação (PDI). Esse instrumento tem sua fundamentação nos preceitos teóricos e metodológicos advindos da
2 - Esse é o grupo inicial de fazendas sendo que, durante a implantação do projeto, outras fazendas podem vir a se agregar, da mesma maneira que pode haver alguma desistência. 
Ciência da Informação e da Ciência de Computação, cujo principal objetivo é o de ser capaz de representar informações referentes aos diferentes tipos de bens patrimoniais, tais como os bibliográficos, arquivísticos, audiovisual, móveis e integrados, construídos, arqueológicos, naturais e os bens imateriais, de forma integrada e relacionada, em termos dos assuntos sobre os quais se reportam os bens patrimoniais. Assim, o principal objetivo deste artigo é apresentar o PDI, bem como aspectos da metodologia utilizada para a sua construção, e o seu potencial de aplicabilidade para a realização de inventário de bens patrimoniais, no universo das fazendas históricas brasileiras.

\section{BREVE HISTÓRICO DO INVENTÁRIO DE BENS PATRIMONIAIS}

A palavra inventário tem sua origem no latim inventarium, termo usado para designar uma grande lista na qual se registravam os produtos dos armazéns; significar elencar, relacionar coisas, artefatos e representações. (MACHADO, 1977) A contabilidade empírica, praticada pelos nossos antepassados, tinha como objeto o registro do patrimônio representado pelos rebanhos, ferramentas de trabalho e outros bens. $\mathrm{O}$ inventário sempre exerceu um importante papel na história da humanidade, uma vez que permite não só a contagem, mas, sobretudo, a classificação dos bens segundo sua natureza: rebanhos, pedras, metais, entre outros. A palavra "Conta" designa o agrupamento de itens da mesma espécie. As primeiras escritas contábeis datam do término da Era da Pedra Polida, quando o homem registrava os seus primeiros desenhos e gravações. Os primeiros controles eram estabelecidos pelos templos e perdurou por muitos séculos. Os sumérios e babilônios, assim como os assírios, faziam os seus registros em peças de argila, retangulares ou ovais, ligeiramente convexas. Os registros combinavam o figurativo com o numérico; por exemplo, o desenho de um animal era correspondente ao número de cabeças existentes. (SCHIMIDT, 2000) A palavra inventário tem diferentes conotações, dependendo da área de conhecimento que dela faz uso. Para efeito deste estudo, adotamos o termo inventário de bens patrimoniais para designar o levantamento e descrição dos bens produzidos por uma comunidade, fruto de sua cultura, visando identificá- 
los, conhecê-los, preservá-los e difundi-los. A atualização desse termo implica no surgimento de classificações não só para representar aspectos quantitativos, mas sobretudo qualitativo que abrangem os conteúdos dos bens inventariado.

A proposta de descrição de bens patrimoniais, que resultará num inventário, aqui apresentada, resulta da análise e avaliação do que vamos chamar de $1^{\text {a. }}$ versão do PDI, (CRISTIANINI et al. 2004) desenvolvida e testada pelo projeto "Memória Virtual de São Carlos". [3] Esse projeto decorreu da iniciativa de um grupo multidisciplinar de pesquisadores e especialistas das áreas de Ciência de Computação, Biblioteconomia e Ciência da Informação, Museologia e Arquitetura, bem como daquelas relacionados aos bens naturais. Esse grupo visou à produção de conteúdos digitais a serem disponibilizados, via Internet. Com esse objetivo investiu no desenvolvimento de um sistema capaz de armazenar, recuperar e divulgar os diferentes tipos de informações, contidas nos mais diversos tipos de fontes, pertencentes aos acervos históricos, situados na cidade de São Carlos, interior do Estado de São Paulo. Observamos que muitos foram os desafios enfrentados e os avanços alcançados pelo grupo pioneiro de pesquisadores e especialistas que ousaram pretender reunir uma série de padrões, nacionais e internacionais, num único sistema que permitisse fazer uso, concomitante, de diversos formatos de registro, que foram reunidos no PDI. (CRISTIANINI et al. 2004) O maior desafio consiste no uso de um único sistema, por meio de equivalência de campos, para descrever dados, informações e conteúdos de naturezas tão diferenciadas, uma vez que estes apresentam um alto grau de especificidade e complexidade. Perseguindo essa premissa, a partir da disponibilização de um protótipo da $1^{\text {a. }}$ versão do sistema de software "Memória Virtual" (NAKAGAWA, E. Y. et al., 2008), foi testada a sua alimentação, com diversos itens de bens patrimoniais, predominantemente, bibliográfico, arquivístico e museológico, que serviram de base para o estudo piloto, tanto da primeira avaliação sobre o desempenho do PDI quanto da primeira versão do software. Naquele momento, a cooperação entre universidades como a USP e
3 - Projeto de Políticas Públicas "Memória Virtual de São Carlos", financiado pela Fapesp, processo número 03/06434-0 com período de vigência de 2004 a 2008, tendo como coordenador geral o Prof. Dr. José Carlos Maldonado do Instituto de Ciências Matemáticas e de Computação da Universidade de São Paulo (ICMC) USP), também membro integrante do Projeto "Patrimônio Cultural Rural Paulista: Espaço Privilegiado para Pesquisa, Educação e Turismo". 
4 - http:// www.icmc.usp.brl museu/ a UFSCar, e o apoio da Prefeitura Municipal de São Carlos, por meio da participação ativa da Fundação Pró-Memória, da Divisão de Arquivo e do Museu e, ainda, a parceria com a Associação Pró Casa do Pinhal, sediada na Fazenda Pinhal - célula mater da fundação da cidade de São Carlos/SP - foram ações fundamentais para o desenvolvimento do sistema "Memória Virtual".

A realização do estudo piloto só foi possível com a participação ativa das três instituições, inicialmente envolvidas e todas sediadas em São Carlos, com seus respectivos acervos e coleções específicas, ou seja, a Associação Pró Casa do Pinhal com itens da coleção bibliográfica histórica, o Arquivo Municipal com itens de uma coleção arquivística e o Instituto de Ciências Matemáticas e de Computação da Universidade de São Paulo (ICMC/USP) com os itens museológicos, pertencentes ao Museu de Computação. [4] Ainda durante o estudo piloto, o PDI foi também aplicado a um pequeno conjunto de dados da ficha cadastral de inventário de bens arquitetônicos, criada pela Fundação Pró-Memória de São Carlos para inventariar os bens imóveis passíveis de preservação, localizados no município de São Carlos/SP. Em relação aos bens "naturais" ou paisagísticos, para efeito de teste de aplicação do PDI, foi tomado como base um roteiro proposto por Costa, Furnival e Krauss (1997) para mapeamento de áreas verdes, espécies e demais elementos da natureza.

A partir desse breve relato, podemos afirmar que a $1^{\text {a. }}$ versão do sistema "Memória Virtual" mostrou-se como de fundamental importância, pois permitiu não só a realização de testes com sucesso do PDI como, também, apontou caminhos promissores para a realização de inventários patrimoniais que vêm merecendo a atenção de pesquisadores, inclusive de outras áreas de conhecimento vinculado ao projeto "Patrimônio Cultural Rural Paulista: Espaço Privilegiado para Pesquisa, Educação e Turismo”. Esses pesquisadores vieram a contribuir com as iniciativas do grupo que atuou na $1^{\text {a. }}$ versão do sistema e, no momento, estão imbuídos dos propósitos de avaliar, aprimorar e ampliar as categorias, os atributos, os requisitos e as 
especificações de propriedades, levando a um refinamento PDI que resultará na $2^{\text {a. }}$ versão do sistema, que passamos a denominar de "Memória Virtual Rural".

PADRÃO DE DESCRIÇÃO INFORMAÇÃO (PDI):

CATEGORIZAÇÕES, ATRIBUTOS E REQUISITOS

Antes de entramos na explanação sobre a categorização de bens e dos respectivos requisitos, atributos e suas propriedades, cujo entendimento torna-se essencial para descrevê-los, esclareceram que, sempre que necessário, estabeleceremos termo de comparação entre as duas versões do PDI. A $1^{\text {a. }}$ versão que se caracteriza pelo padrão usado no desenvolvimento do sistema protótipo denominado "Memória Virtual" que foi usado para teste e a $2^{\text {a. }}$ versão do PDI, derivada da $1^{\text {a. }}$ versão, contendo os acréscimos e desdobramentos que estão resultando no desenvolvimento do sistema, agora intitulado "Memória Virtual Rural". Entendemos que esse processo de "versões" se faz necessário diante do ineditismo com relação às características e abrangência dos bens patrimoniais a serem descritos, nos furtando, naquele momento, de termos como base outras experiências. Assim, as preocupações dos pesquisadores concentraram-se, desde a $1^{\text {a. }}$ versão, na identificação dos requisitos e atributos, capazes de gerar metadados e conteúdos sobre fazendas históricas, que norteassem o desenvolvimento do sistema de software, conforme foi ressaltado por Cristianini et al. (2004)

Nessa ampla abordagem dos bens patrimoniais, logo pudemos constatar que um PDI deveria ser construído a fim de acolher todo o detalhamento e a complexidade que se apresenta para atender aos anseios dos pesquisadores e, ao mesmo tempo, dos gestores das fazendas históricas e, ainda, de um amplo público que se caracteriza como potencial usuário. Nesse contexto, percebemos que precisávamos criar mais campos descritivos e abrir um grande leque de opções que pudessem abrigar outros tipos de bens, com atributos específicos; porém, de forma articulada, dialógica e integrada. Essa constatação, do ponto de vista de um observador, pode parecer, à primeira vista, algo inexequível. Todavia, os propósitos do nosso projeto estão sendo perseguidos e a descrição de todos os tipos os bens patrimoniais está sendo prevista de forma integrada, em uma mesma 
interface de entrada de dados, que permite descrever tanto dados gerais, comuns a todos e qualquer bem, quanto às especificidades, pertinentes apenas a um determinado tipo de bem. Esse processo resultará num grande repositório que prevê a total interoperabilidade, inclusive semântica, entre os diferentes tipos de bens patrimoniais inventariados.

A ideia central, que nos acompanha desde a $1^{\text {a. }}$ versão do PDI e da base de dados do sistema "Memória Virtual", é o fato dessa base se diferenciar de outras bases de dados, principalmente as bibliográficas, diante da possibilidade de se criar uma correspondência conceitual entre os diferentes níveis de descrição adotados para cada conjunto ou item, de acordo com a sua natureza e tipologia, como por exemplo, os bens arquitetônicos (conjunto, sub-conjunto e parte de edificações), arquivístico (fundo, série, sub-série, dossiê, processo e documento), bibliográfico (coleção, série documental e parte de documento), bem móvel ou museológico (coleção, série, peça e parte de peça ou objeto), natural ou paisagístico (classe, subclasse, família, gênero, espécie e paisagem) e ainda os bens imateriais.

No desenvolvimento da $1^{\text {a. }}$ versão do PDI, a descrição nos diferentes níveis que envolvem cada tipo de acervo ou coleção requereu a necessidade de se mapear um grande rol de atributos e requisitos e de se estabelecer a sua correspondência com uma estrutura que viria a servir de apoio para a construção do sistema "Memória Virtual". Desse processo, resultaram os agrupamentos de atributos, de acordo com características semelhantes ou diferentes, em relação à natureza dos metadados e dos conteúdos previstos para cada campo, conforme explicitam Cristianini et al. (2004) No caso do PDI, a definição dos atributos a priori foi fundamental para garantir o detalhamento necessário, para cada grupo de conteúdo a ser introduzido na base de dados do sistema "Memória Virtual", durante a fase piloto feita com a $1^{\text {a. }}$ versão. Podemos entender que um atributo é um valor dado ou atribuído ou a uma classe dados, categoria ou grupo de bens patrimoniais. Por exemplo, autoria é um atributo de "pessoa", enquanto estilo é um atributo do objeto "casa" e são esses atributos que permitem descrever, mais detalhadamente, um bem patrimonial. Num primeiro momento, quando da $1^{\text {a. }}$ versão do PDI, esses atributos foram subdivididos em dez grupos, conceitualmente bastante abrangente, de acordo com os seus res- 
pectivos conteúdos. Num segundo momento, quando da revisão e avaliação da $1^{\text {a. }}$ versão do PDI, o rol de atributos ganhou outras especificidades de descrição e dos diferentes níveis de cada tipo de bem, em função de uma ampliação das áreas de interesse que levou à necessidade de identificarmos outros atributos que respondessem às exigências de novos itens patrimoniais e novos conteúdos. Essa ampliação, consequentemente, deu origem a uma nova estrutura que servirá de apoio para a construção do sistema "Memória Virtual Rural". Vale destacar ainda que essa importante atividade contou com pesquisadores das mais diversas áreas do conhecimento, dentre elas a Arquitetura, Arquivologia, Ciência de Computação, Ciência da Informação, Ciências Sociais, Educação, Turismo, História, Agronomia e Museologia, entre outras áreas e especialidades.

A análise e a identificação de novos atributos geraram uma nova matriz de códigos, normas e roteiros, que se somaram aos iniciais e que fornecem os subsídios para se estabelecer os parâmetros para a coleta de dados, a descrição e a geração de conteúdos. Dentre as principais fontes que compõem essa matriz, podemos destacar: o Anglo-American Cataloguing Rules (AACR2), [5] para descrição de documento bibliográfico, a General International Standard Archival Description (ISAD(G)), para documentos de arquivo do International Council on Archives (ICA), (ICA, 2000) o Dublin Core (DUBLIN CORE METADATA ELEMENT, Version 1.1) e a Encoded Archival Description (EAD) (EAD: ENCODED ARCHIVAL DESCRIPTION, Version 2002), para facilitar a descrição de recursos eletrônicos, o sistema de descrição usado pelo Instituto do Patrimônio Histórico e Artístico Nacional (IPHAN), expresso pelo Sistema Integrado de Conhecimento e Gestão (SICG) (SISTEMA, 2010), bem como um sistema usado pela Prefeitura Municipal de Uberlândia/MG. Em relação aos bens iconográficos, particularmente a descrição de imagens fotográficas, o PDI foi comparado com os padrões usados pelo Centro de Memória-Unicamp (CMU) e pelo Sistema de Apoio à Comunicação Integrada (SACI), desenvolvido pela UFSCar. Além dessas fontes, restam ainda maior aprofundamento em relação ao formato de registro MARC (Machine Readable Cataloging) para identificação, armazenamento e intercâmbio de dados bibliográficos (LIBRARY, 2010) e o estudo de Corti (1992) que $5-\underline{h t t p: / /}$

www.aacr2.orgl 
certamente contribuirão para o refinamento do PDI.

Ao realizarmos um estudo comparativo, entre esses vários sistemas analisados, revelou-se a exaustividade e a completeza com que vem se configurando o PDI, visando a dar subsídios à implementação do sistema "Memória Virtual Rural". Observa-se que 34,5\% dos campos e sub-campos do PDI, ou seja, 40 de 116 campos e subcampos, não são abordados por nenhuma das outras fontes citadas anteriormente, conforme pode ser visualizado no Gráfico 1. Esse estudo comparativo ainda revelou que dentre os 116 campos e sub-campos do PDI, 26 deles se equiparam aos do CMU, 51 coincidiram com os do IPHAN, 13 com o sistema SACI e 19 tiveram semelhança com o Sistema de Inventário da Prefeitura Municipal de Uberlândia. O PDI revelou também quais os pontos fortes e fracos de cada uma das fontes utilizadas, bem como as suas especialidades e como elas podem ser exploradas pelo PDI.

Visando ilustrar o PDI, na Figura 1 é mostrada a estrutura geral do PDI. Observa-se que o padrão é subdividido em 13 grupos de campos, sendo que no Quadro 1 é apresentado em mais detalhes a descrição cada um desses grupos.

Vale ainda destacar que cada um desses grupos se desdobra em um

Gráfico 1: Comparação entre campos e sub-campos do PDI e de outros sistemas de descrição

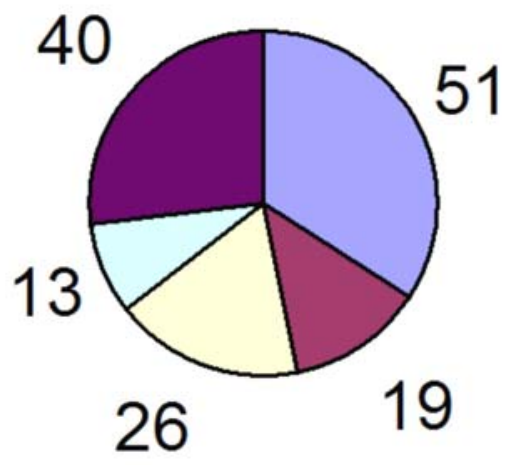
$\square$ IPHAN

口PREF. UBERLÂNDIA

$\square \mathrm{CMU}$

$\mathrm{SACl}$

$\square$ CAMPOS NOVOS 
Figura 1: Estrutura Geral do PDI

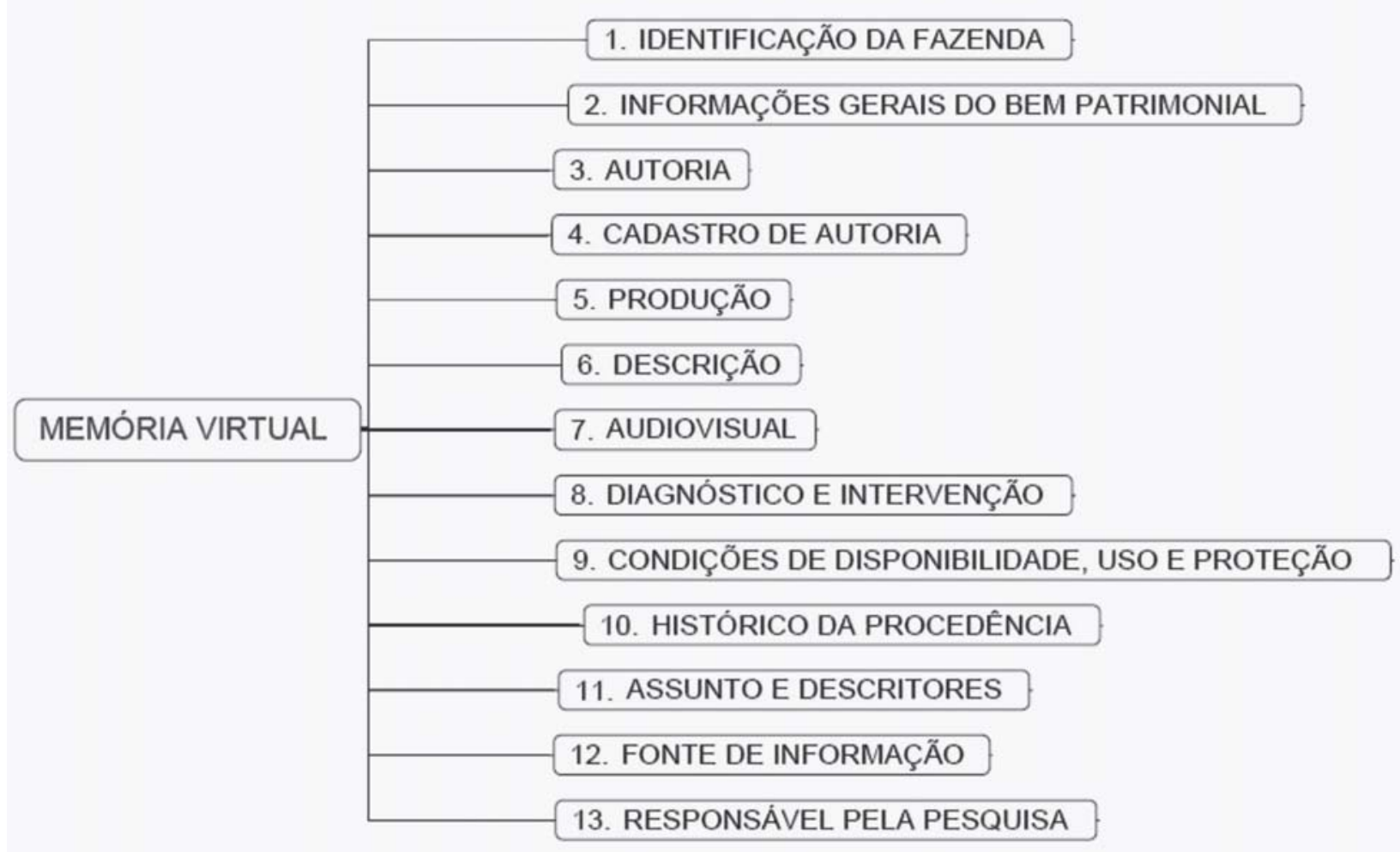

conjunto maior de campos, buscando contemplar as especificidades de cada grupo. Por exemplo, na Figura 2, é mostrado parte do refinamento dado ao Grupo 1 referente às informações gerais do bem patrimonial. Observa-se os nomes dos campos (por exemplo, "2.4 Título"), os subcampos (por exemplo, "2.4.1. Tipo do título"), as possibilidades de escolha com valores pré-estabelecidos (por exemplo, os tipos de títulos existentes) e disponibilização de textos explicativos para os campos (indicados por balões). Essa mesma organização é encontrada nos demais 12 grupos do PDI.

Esse estudo demonstra a exaustividade e a completeza com que vem se configurando o PDI que reúne uma diversidade de campos e subcampos e apresenta-se como um elemento fundamental em termos do fornecimento dos requisitos necessários à construção do sistema "Memória Virtual Rural”. 
MODELAGEM DO SISTEMA MEMÓRIA VIRTUAL RURAL

Com base no PDI, o sistema Memória Virtual Rural tem sido projetado e posteriomente deverá ser implementado com tecnologias de computação. Para isso, um conjunto amplo de modelos de sistemas foi desenvolvido,

Quadro 1: Descricão dos Grupos do PDI

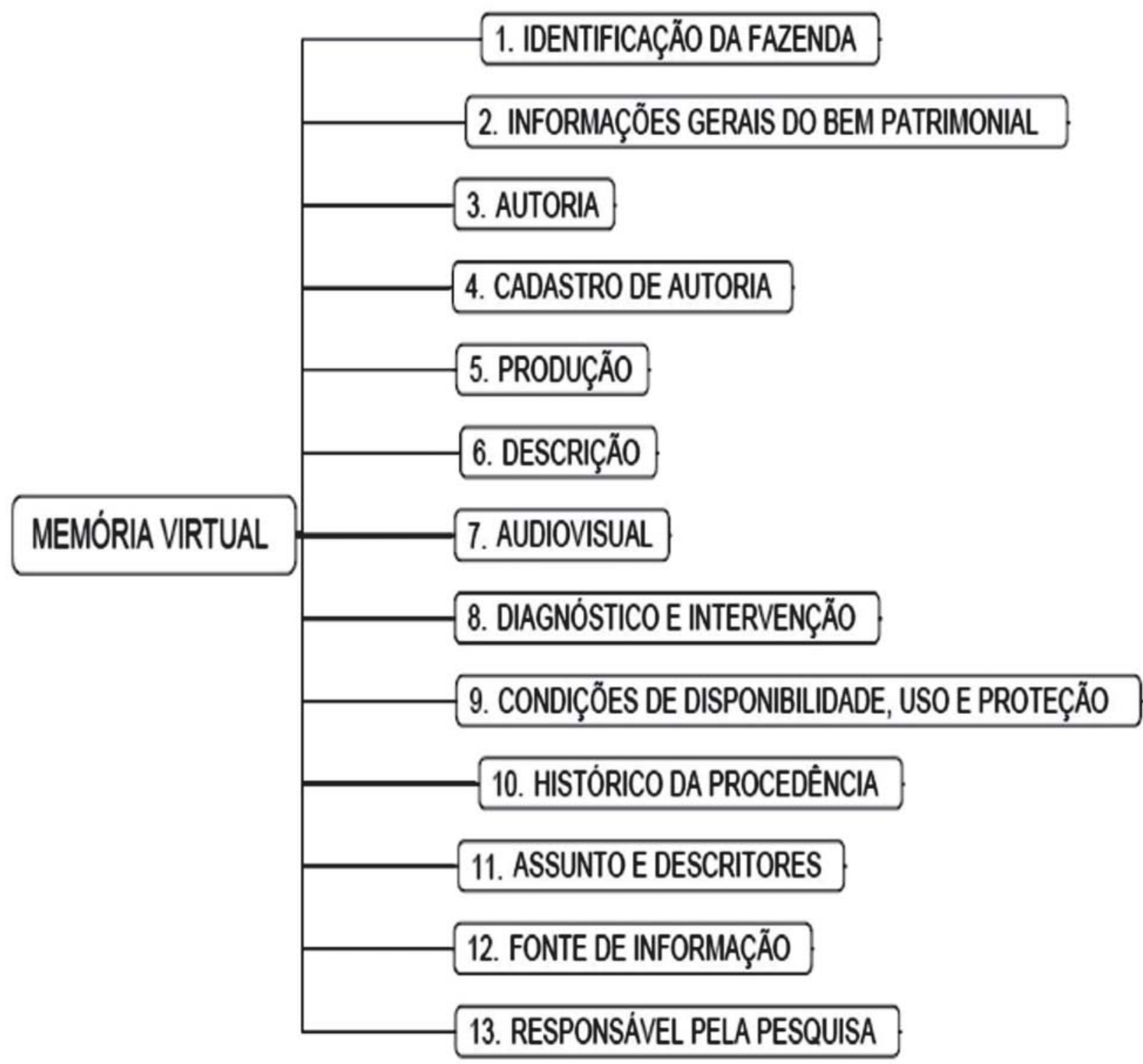

48 RESGATE - Vol. XVIII, №. 20 - jul./dez. 2010 - NAKAGAWA, Elisa; COSTA, Luzia; SCARPELINE, Rosaelena - p.37-53 
Figura 2: Refinamento do Grupo 1: Informações Gerais do Bem Patrimonial

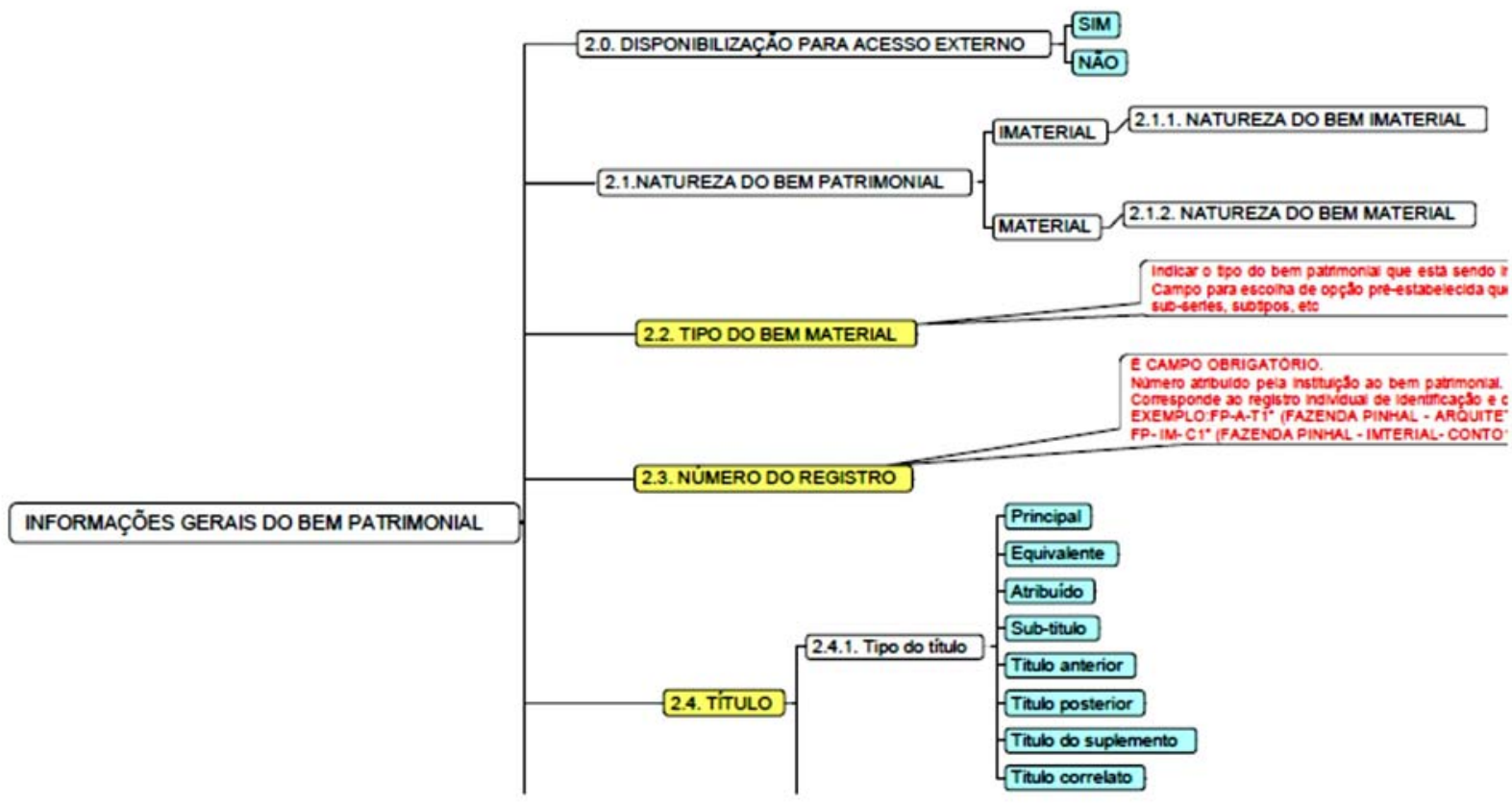

Figura 3: Diagrama de Casos de Uso do Sistema Memória Virtual Rural

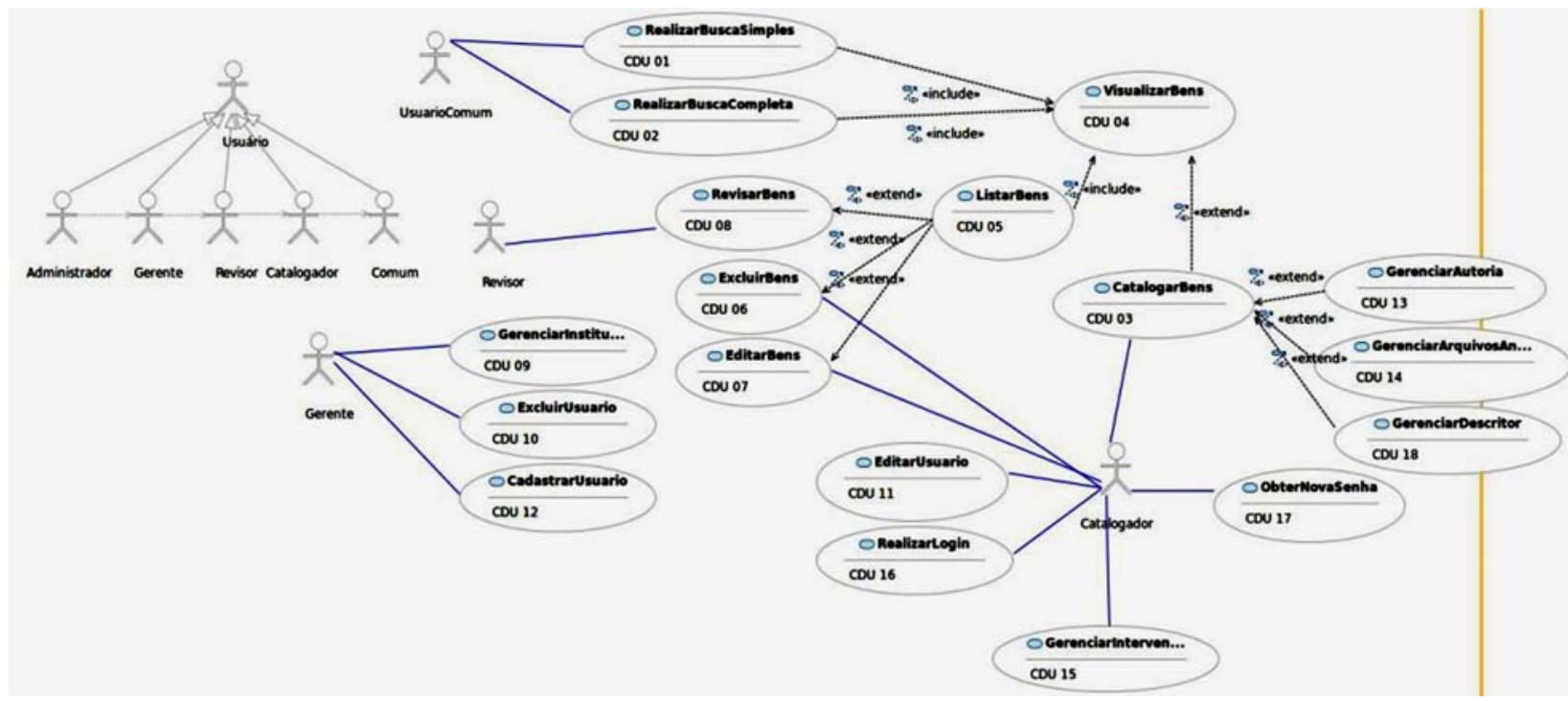


buscando-se registrar a estrutura da base de dados, a arquitetura do sistema, bem como as funcionalidades que devem estar disponíveis no sistema. Por exemplo, na Figura 3 é apresentado o Diagrama de Casos de Usos. Esse diagrama é fundamental, uma vez que registra os tipos de usuário do sistema, bem como as funcionalidades que devem estar disponíveis no sistema para cada tipo de usuário. Observa-se que os usuários desse sistema são: administrador, gerente, revisor, catalogador e usuário comum, sendo que cada um deles pode ter acesso a funcionalidades específicas. Por exemplo, o usuário comum poderá "RealizarBuscaSimples" e "RealizarBuscaCompleta", como mostrado pelos casos de uso associados a esse tipo de usuário. Esse diagrama é também fundamental para definir a interface do sistema com o ambiente, ou seja, ele define como o ambiente (composto pelos diferentes tipos de usuário) irá interagir com o sistema. Dessa forma, é possível ter uma visão geral das funcionalidades necessárias no sistema.

Além dos modelos que representam as funcionalidades do sistema,

Figura 4: Protótipo da Interface Web do Usuário

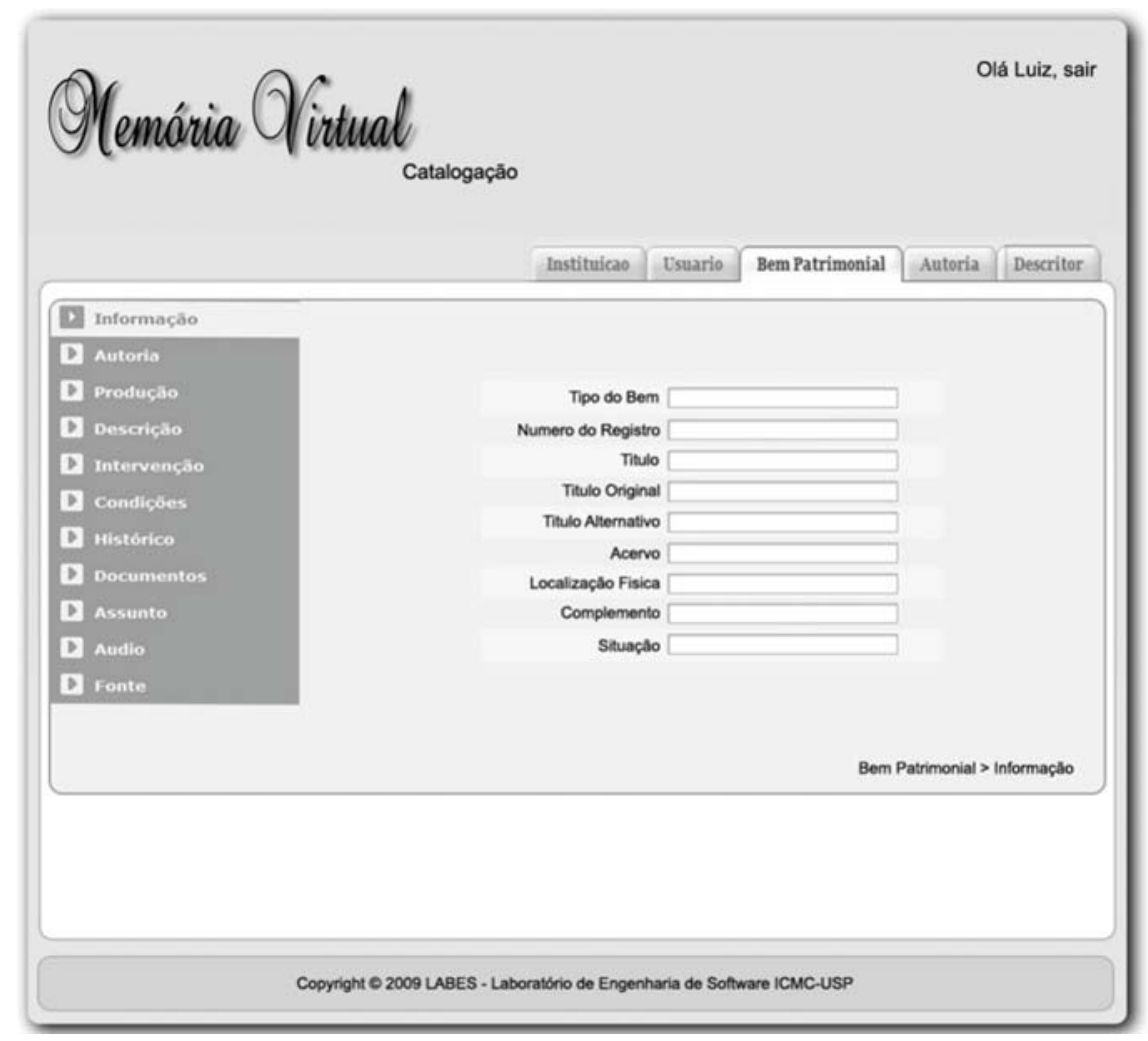


foram também desenvolvidos protótipos da interface web do usuário do Sistema Memória Virtual Rural, visando ter uma interface com mais usabilidade e mais adequado ao domínio de fazendas históricas. Na Figura 4 é apresentado um dos protótipos desenvolvidos. É importante ressaltar que esses protótipos têm papel fundamental no entendimento dos requisitos e das funcionalidades que o sistema deverá disponibilizar. Esses protótipos serão mais tarde a base da implementação do sistema Memória Virtual Rural e ficará disponível livremente, ao público interessado.

Cabe por fim considerar que as iniciativas do grupo de pesquisadores, envolvidos no desenvolvimento da $1^{\text {a. }}$ versão do PDI e do sistema "Memória Virtual", foram de fundamental importância para o estabelecimento da $2^{\text {a. }}$ versão do PDI. Foram esses estudos que permitiram não só o surgimento de uma nova perspectiva de pesquisa original, visando catalogar e inventariar todo e qualquer bem patrimonial, independente da sua tipologia e natureza. Da mesma forma, a participação de um grupo maior de pesquisadores de novas áreas de conhecimento e de diferentes outras instituições permitiu que se avançasse significativamente em exaustividade e aprofundamento em relação às categorias e seus atributos.

Os avanços nos estudos para o estabelecimento da $2^{\text {a. }}$ versão do PDI apresentaram até o momento resultados concretos e imediatos e outros que se traduzem em expectativas de possíveis desdobramentos. Dentre os resultados mais palpáveis, além de atender às necessidades de descrição de um amplo espectro de bens patrimoniais, está a organização de um "Documento de Referência Terminológica" contendo os conceitos e definições mais usuais no contexto do projeto, permitindo não só uma melhor comunicação entre pesquisadores e especialistas envolvidos no projeto; mas sobretudo, a elaboração do manual de instrução no qual os procedimentos previstos para cada campo e subcampos do PDI estarão definidos e exemplificados.

Além disso, nesse estudo, percebemos facilmente o entrelaçamento de muitos campos teóricos e das possíveis frentes que se abrem, tais como a necessidade de fazermos intervenções no que tange à organização e ao gerenciamento da informação e do conhecimento com o uso de ferramentas que assumam o papel de fazer a interoperabilidade semânti- 
ca, integrando dados e conteúdos, contribuindo, assim, para que as informações originalmente isoladas sejam utilizadas de maneira integrada.

Num futuro próximo pretendemos construir a base de dados do sistema "Memória Virtual Rural" com base na $2^{\text {a. }}$ versão do PDI. Tendose essa base de dados, funcionalidades serão implementadas nesse sistema de modo a possibilitar a organização e catalogação de informações dos mais diversos tipos de bens patrimoniais pertencentes às fazendas históricas paulista, bem como a disponibilização dessas informações por meio da plataforma web.

Em síntese, na medida em que o projeto avança, permite nos perceber que o PDI vai refletir diretamente na configuração da base de dados e dos diferentes níveis de exigência, uma vez que não estamos somente em busca de coleta e armazenamento de metadados ou dados descritivos, mas também de dados analíticos. Almejamos assim que o sistema "Memória Virtual Rural” possa proporcionar elementos para que possamos desenvolver não só textos descritivos, mas também textos analíticos e interpretativos, traduzindo os sentidos e os significados que nos permitem atribuir, cada vez mais, relevância científica, histórica e social aos acervos e coleções representativas do patrimônio material e imaterial, no âmbito das fazendas paulistas.

Finalmente, queremos ainda registrar que no universo das fazendas históricas paulistas, as possibilidades não se esgotam, uma vez que encontramos um território promissor com múltiplas possibilidades de descoberta e que revelam a grande diversidade de bens patrimoniais raros e de valor inestimável, do ponto de vista do patrimônio histórico, cultural e natural. É importante ressaltar ainda a sua importância como elemento de formação da identidade, da cidadania e do pertencimento a um determinado contexto espaço-temporal.

\section{REFERENCIAS BIBLIOGRÁFICAS}

CORTI, L. Beni Culturali: Standards di Reppresentzione, Descrizione e Vocabolario. Modena: Franco, Cosimo e Panini, 1992.

CRISTIANINI, G. M. S.; MORAES, J. S.; MORAES, L. S.; NAKAGAWA, E. Y;; "Conteúdos digitais e padrões de registros: desafios para a democratização de 
acervos especiais”. Seminário Nacional de Bibliotecas Universitárias, 13 (SNBU'2004). Anais..., 17 a 21 de outubro de 2004, Natal, RN, p. 1-14.

Dublin Core Metadata Element, version 1.1. Disponível em: http:// dublincore.org/documents/dces/. Acesso em: 03 dez. 2010.

EAD: Encoded Archival Description, Version 2002. Disponível em: http:// www.loc.gov/ead/. Acesso em: 03 dez. 2010.

FERNANDES, L. S.; FURNIVAL, A.C. "Informação para educação ambiental: proposta para a criação de um centro de referência”. In: Seminário de Ciência e Desenvolvimento Sustentável. Anais... São Paulo: IEA/USP, 1997.

ICA - International Council on Archives. $\operatorname{ISAD}(G)$ : General International Standard Archival Description. 2.ed. Ottawa: ICA, 2000. Disponível em: < http://www.ica.org/en/node/30000 > Acesso em: $01 \mathrm{dez} .2010$.

Library of Congress. Understanding MARC Bibliographic: Machine-Readable Cataloging. Washington, DC: LC, 2003. Disponível em: <http://www.loc.gov/ marc/umb> Acesso em: 01 dez. 2010.

MACHADO, J. P. Dicionário Etimológico da Língua Portuguesa. Lisboa: Livros Horizonte, 1977.

NAKAGAWA, E. Y. et al. Software Architecture Relevance in Open Source Software Evolution: A Case Study, In: IEEE International Workshop on Quality and Architectural Concerns in Open Source Software (QACOS 2008), IEEE International Computer Software and Applications Conference (COMPSAC'2008). Anais..., 28 de julho a 01 de agosto de 2008, Turku, Finland, p. 1234-1239.

Patrimônio Cultural Paulista. Condephaat: Bens tombados 1968-1998. São Paulo: Imprensa Oficial do Estado, 1998.

SCHIMID, P. História do Pensamento Contábil. Porto Alegre: Bookman, 2000.

SISTEMA Integrado de Conhecimento e Gestão: SICG. Disponível em

< http://portal.iphan.gov.br/portal/ >. Acesso em: 01 dez. 2010.

SOUSA, M. N. M.; CANDELOT, V. L. R. Projeto Inventário do Museu Municipal de Uberlândia. Uberlândia: Prefeitura Municipal, 2007. Disponível em: 〈http://app01.museudoindio.gov.br/dowloads/>. Acesso em 09 jan. 2010. 